\title{
Ivabradine inhibits carbachol-induced contractions of isolated rat urinary bladder
}

\author{
Hasan Riza Aydin ${ }^{1, A, B}$, Hasan Turgut ${ }^{2, B, C}$, Ayşegül Kurt ${ }^{3, B, C}$, Ramazan Sahan ${ }^{3, B, C}$, \\ Ömer Faruk Kalkan ${ }^{3, B, C}$, Huseyin Eren ${ }^{4, A, F}$, Ahmet Ayar ${ }^{3, A, C, D, F}$ \\ 1 Department of Urology, University of Health Sciences, Trabzon Kanuni Training and Research Hospital, Turkey \\ 2 Department of Urology, Akcaabat Hackali Baba State Hospital, Trabzon, Turkey \\ ${ }^{3}$ Department of Physiology, Faculty of Medicine, Karadeniz Technical University, Trabzon, Turkey \\ ${ }^{4}$ Department of Urology, Faculty of Medicine, Recep Tayyip Erdogan University, Rize, Turkey \\ A - research concept and design; B - collection and/or assembly of data; $\mathrm{C}$ - data analysis and interpretation; \\ $D$ - writing the article; $E$ - critical revision of the article; $F$ - final approval of the article
}

Address for correspondence

Ahmet Ayar

E-mail: aayar61@yahoo.com

Funding sources

None declared

Received on February 9, 2017

Reviewed on March 9, 2017

Accepted on May 9, 2017

\begin{abstract}
Background. Overactive bladder (OAB), a symptom syndrome defined as urgency, is a common clinical condition, which sometimes cannot be satisfactorily treated with current medications in every subject; therefore, alternatives are needed.
\end{abstract}

Objectives. The aim of this in vitro study was to investigate the effects of ivabradine, a selective pacemaker If current inhibitor, on agonist-induced isometric contractions of the bladder smooth muscles.

Material and methods. Urinary bladder strips were isolated from adult male Wistar rats and suspended in a tissue bath containing physiological solution. The strips were contracted by bath applications of carbachol (CCh, $1 \mu \mathrm{M})$. Ivabradine (30 $\mathrm{MM}, 60 \mu \mathrm{M}$ or $90 \mu \mathrm{M})$ was added to the tissue bath either prior to or after the application of the agonist, and the resulting contractile activity was compared to the preceding contractile activity. The amplitude and area under force-time curves (AUFC) of the isometric contractions were evaluated.

Results. The addition of CCh caused a marked stimulation of contractile force in isolated urinary bladder strips, which was significantly inhibited by ivabradine, both in terms of peak amplitude (29\% $\pm 3 \%, 20 \% \pm 6 \%$ and $18 \% \pm 6 \%$ by $30 \mu \mathrm{M}, 60 \mu \mathrm{M}$ and $90 \mu \mathrm{M}$ ivabradine, respectively) and AUFC ( $47 \% \pm 5.5 \%, 35 \% \pm 8 \%$ and $35 \% \pm 6 \%$ by $30 \mu \mathrm{M}, 60 \mu \mathrm{M}$ and $90 \mu \mathrm{M}$ ivabradine, respectively; $n=7$ for each). Pre-treatment with ivabradine $(10 \mu \mathrm{M})$ significantly attenuated the contractile response to $C \mathrm{Ch}(1 \mu \mathrm{M}$; mean peak amplitude from $1493 \pm 216 \mathrm{mg}$ to $680 \pm 95 \mathrm{mg} ; \mathrm{p}<0.003 ; n=7$ ).

Conclusions. The results of this in vitro study demonstrated that ivabradine inhibits cholinergic agonistinduced bladder contractions, which means that in the future ivabradine may be used in OAB treatment.

Key words: urinary bladder, overactive bladder, ivabradine

DOI

10.17219/acem/71197

\section{Copyright}

Copyright by Author(s)

This is an article distributed under the terms of the

Creative Commons Attribution Non-Commercial License

(http://creativecommons.org/licenses/by-nc-nd/4.0/) 


\section{Introduction}

The urinary bladder is a distensible, membranous, hollow organ, made of a thin layer of smooth muscle that provides its unique properties of relaxing to accommodate and contracting to empty out urine, one of the body's continuously produced fluid waste products. The smooth muscle wall of the bladder, also known as the detrusor, and the internal sphincter, the internal continuation of the detrusor, are under autonomic control, while the external urethral sphincter is under somatic control from higher centers. ${ }^{1}$ The bladder temporarily stores urine until the person finds appropriate time and place to eliminate it from the body by coordinated actions of autonomic and somatic muscles that encircle the bladder neck. ${ }^{2}$

Thus, the process of physiological control of urination, notably the reflex contraction of the detrusor muscle, involves highly complex coordination between the central, autonomic and somatic nervous systems, and has been reviewed extensively elsewhere. ${ }^{3,4}$ As the bladder fills up with urine and its volume reaches about $200 \mathrm{~mL}$ or more (bladder functional capacity is $300-600 \mathrm{~mL}$ ), the stretch receptors in the bladder excite and send signals to higher centers, and the voluntary voiding is usually initiated. However, the detrusor can become too active and contract involuntarily, making the individual feel the urge to void inappropriately, even when the bladder has little urine. This clinical symptom is referred to as overactive bladder (OAB), typically caused by spasms of the bladder muscles with or without incontinence. ${ }^{5}$ Overactive bladder is a very common chronic condition that affects the daily lives of a huge number of men, women and children worldwide. ${ }^{5,6}$ Urinary urgency, frequent urination and nocturia are a common set of OAB symptoms that can be caused by a wide range of conditions, including detrusor hyperreflexia, urinary tract infections and obstructive prostatic hypertrophy. ${ }^{5,6}$ Whatever the underlying cause, intense and involuntary bladder muscle contractions are present. Although symptoms can range in severity from mild to very severe, $\mathrm{OAB}$ is a condition that often requires treatment. And, despite a range of available treatment options, just as the etiology of $\mathrm{OAB}$ is often multifactorial, the treatment approaches and available tools are far from satisfactory.

Basic research studies of isolated bladder smooth muscle tissue have made important contributions to our current understanding of the physiology of the bladder, as well as the development of new and improved approaches for the control of clinically relevant detrusor contractility impairments, ranging from underactivity to overactivity, including OAB.

The "funny" (If) current (or funny channel or pacemaker current), originally described in the sinoatrial (SA) node and Purkinje fibers, is currently being investigated for its potential role(s) in smooth muscles with the capacity of generating spontaneous phasic activity. ${ }^{7-10,11}$ Evidence is being accumulated that interstitial cells of Cajal (ICCs) and ICC-like cells possess the general and specific properties of pacemaker cells. Although less studied than those in cardiac tissue, they are ubiquitously expressed in smooth muscle tissues of many organs, including the gastrointestinal tract, uterine, lymph ducts, urinary bladder, and urethra. ${ }^{8,9}$ The pacemaker structures have been suggested to contribute to spontaneous contractions of these smooth muscle tissues by funny currents (If currents) through hyperpolarization-activated cyclic nucleotide-gated (HCN) channels. ${ }^{9,12}$ Indeed, the self-contractibility of the urinary bladder through myogenic excitation implicates a potential bladder pacemaker, possible through the signals from ICCs. Interstitial cells of Cajal, a group of cells present in the wall of the bladder, are suggested to play a role in $\mathrm{OAB}$, although there is no clear evidence of signal transmission. Still, the results of a clinical study have implied that the use of ivabradine, a selective blocker of pacemaker If current, could possibly be used in the treatment of OAB. ${ }^{13}$ However, studies involving the possible effects of ivabradine on smooth muscle contractility have never been carried out.

Hence, the aim of this in vitro study was to investigate the possible effects of ivabradine on agonist-stimulated contractions of isolated rat bladder smooth muscles.

\section{Material and methods}

\section{Tissue preparation}

The protocol of this study was reviewed and approved by the local Ethics Committee.

Adult male Wistar rats (250-300 g), obtained from the Karadeniz Technical University Surgical Research Center, Trabzon, Turkey, were sacrificed by cervical dislocation, and the urinary bladder was exposed by a midline incision of the abdomen. The urinary bladder was removed by cutting at the bladder neck and placed in a physiological saline solution (PSS) containing: $120 \mathrm{mM} \mathrm{NaCl}$, $5.9 \mathrm{mM} \mathrm{KCl}, 2.5 \mathrm{mM} \mathrm{CaCl}_{2}, 1.1 \mathrm{mM} \mathrm{MgCl}_{2}, 15 \mathrm{mM}$ $\mathrm{NaHCO}_{3}, 1.2 \mathrm{mM} \mathrm{NaH}_{2} \mathrm{PO}_{4}, 11 \mathrm{mM} \mathrm{C}_{6} \mathrm{H}_{12} \mathrm{O}_{6}$ (glucose), and $10 \mathrm{mM} \mathrm{C}_{8} \mathrm{H}_{18} \mathrm{~N}_{2} \mathrm{O}_{4} \mathrm{~S}$ (HEPES). The bladder was cut open from the base to the dome and strips were prepared $(\sim 15 \mathrm{~mm} \times 3 \mathrm{~mm} \times 2 \mathrm{~mm})$.

\section{Recording of isometric tension}

Bladder strips were mounted in $10 \mathrm{~mL}$ organ baths filled with PSS at $37^{\circ} \mathrm{C}$ and $\mathrm{pH} 7.4$, constantly bubbled with $95 \%$ oxygen $-5 \%$ carbon dioxide, and the isometric contractions were recorded. The lower end of the strip was fixed to a metal hook and the upper end was attached to an isometric force-displacement transducer (FTD 10A; Commat Ltd., Ankara, Turkey), and the signals were amplified and recorded through a data acquisition system (MP100 Data Acquisition System; Biopac Systems Inc., Goleta, USA). 
The strips were allowed to equilibrate under a passive resting tension of $1 \mathrm{~g}$ for $45 \mathrm{~min}$, and then the strips were contracted by bath applications of carbachol (CCh, $1 \mu \mathrm{M})$. Ivabradine $(30 \mu \mathrm{M}, 60 \mu \mathrm{M}$ and $90 \mu \mathrm{M})$ was added to the tissue bath either prior to or after application of the agonist, and the resulting contractile activity was compared with the preceding contractile activity. The amplitude and area under force-time curves (AUFC) of the isometric contractions were evaluated and compared, averaged over 10 -minute intervals.

\section{Chemicals}

Ivabradine, CCh and all constituents of the PSS were purchased from Sigma (Deisenhofen, Germany) and were of research grade. Ivabradine and $\mathrm{CCh}$ were dissolved in the PSS, and were added to the tissue bath at the indicated concentrations.

\section{Statistical analysis}

All statistical analyses and graphics were performed using the Microcal Origin v. 5.00 computer program (Microcal Software Inc., Northampton, USA). The data is expressed as the arithmetic mean of the "n" number of experiments and the standard error of mean (SEM). Statistical significance was analyzed by Student's t-test. The probability value of $\mathrm{p}<0.05$ was considered significant.

\section{Results}

In 3 out of the 22 strips studied, the bath application of CCh caused a marked stimulation of contractile force in isolated bladder strips. The remaining non-responding 3 strips were not further utilized for the study.

The application of ivabradine attenuated the peak amplitude of the CCh-induced contractions in a concentration-dependent manner. The peak amplitude of the contractions was reduced to $29 \% \pm 3 \%$ ( $p<0.001$ ), $20 \% \pm 6 \%$ ( $\mathrm{p}<0.001)$ and $18 \% \pm 6 \%(\mathrm{p}<0.001)$ of the CCh-induced period (100\%) after the application of $30 \mu \mathrm{M}, 60 \mu \mathrm{M}$ and $90 \mu \mathrm{M}$ ivabradine, respectively (Fig. 1-3). Ivabradine caused a similar attenuation in the AUFC values for CChevoked contractile responses. On the average, the normalized AUFC values of CCh-induced contractions was reduced to $47 \% \pm 5.5 \%(\mathrm{p}<0.01), 35 \% \pm 8 \%(\mathrm{p}<0.01)$ and $35 \% \pm 6 \%$ ( $\mathrm{p}<0.01)$ ( $\mathrm{n}=7$ for each) of the CCh-induced period (100\%) after the application of $30 \mu \mathrm{M}, 60 \mu \mathrm{M}$ and $90 \mu \mathrm{M}$ ivabradine, respectively (Fig. 1-3).

In additional experiments, the strips of bladder were pre-treated with ivabradine. Pre-treatment with ivabradine significantly inhibited the contractile response to $\mathrm{CCh}$ without significantly effecting the resting tension (Fig. 4). Accordingly, ivabradine $(10 \mu \mathrm{M})$ was applied before CChstimulation $(1 \mu \mathrm{M})$, and the mean peak amplitude of these
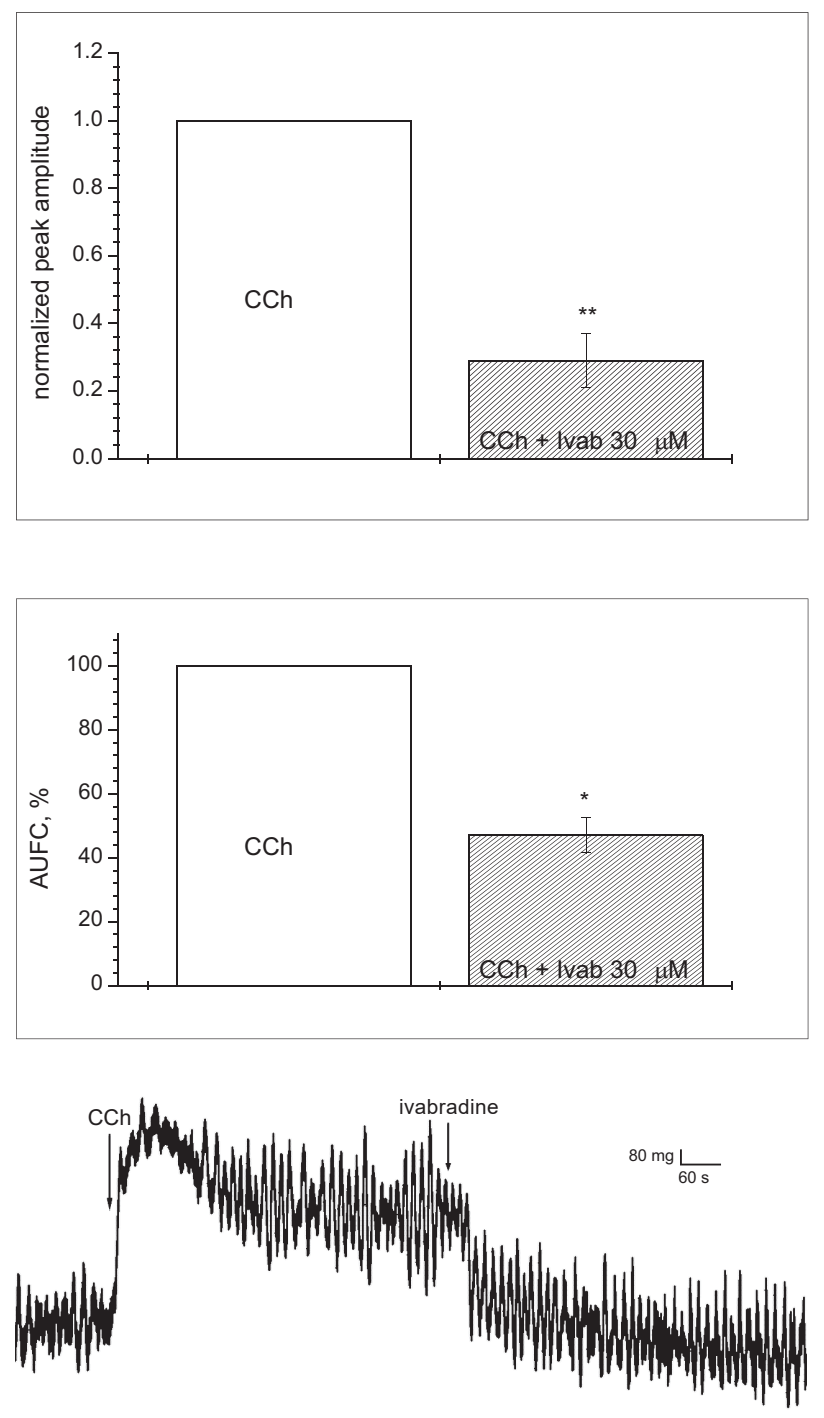

Fig. 1. Effect of $30 \mu \mathrm{M}$ ivabradine on the carbachol (CCh, $1 \mu \mathrm{M})$-induced contractions of rat bladder strips; normalized amplitude of CCh-evoked contractions and area under force-time curve (AUFC)

Results are expressed as mean $\pm \mathrm{SE}_{;}^{*}{ }^{*} \mathrm{p}<0.01$ compared to the CCh-induced response period prior to ivabradine application $(n=7)$; ** $p<0.001$ compared to the CCh-induced response period prior to ivabradine application $(n=7)$.

A representative tracing illustrating the contractile activity of bladder strip preparations in response to carbachol $(C C h, 1 \mu \mathrm{M})$ and the inhibition of the contractile activity by ivabradine. Bladder strips developed a sustained tension in response to CCh, and ivabradine was applied at the indicated point and was continuously present afterwards.

contractions were significantly weaker when compared to the contractile response to $\mathrm{CCh}$ alone $(680 \pm 95 \mathrm{mg}$, $\mathrm{n}=7$ vs $1493 \pm 216$ mg; $\mathrm{n}=7 ; \mathrm{p}<0.003$ ) (Fig. 4).

\section{Discussion}

The results of the present in vitro study demonstrated, for the first time, that ivabradine inhibits cholinergic agonist-induced contraction of the rat bladder. This is the first evidence that the If channel inhibitor - ivabradine directly blocks bladder muscle contractility, implying that it might be useful in the treatment of OAB. 

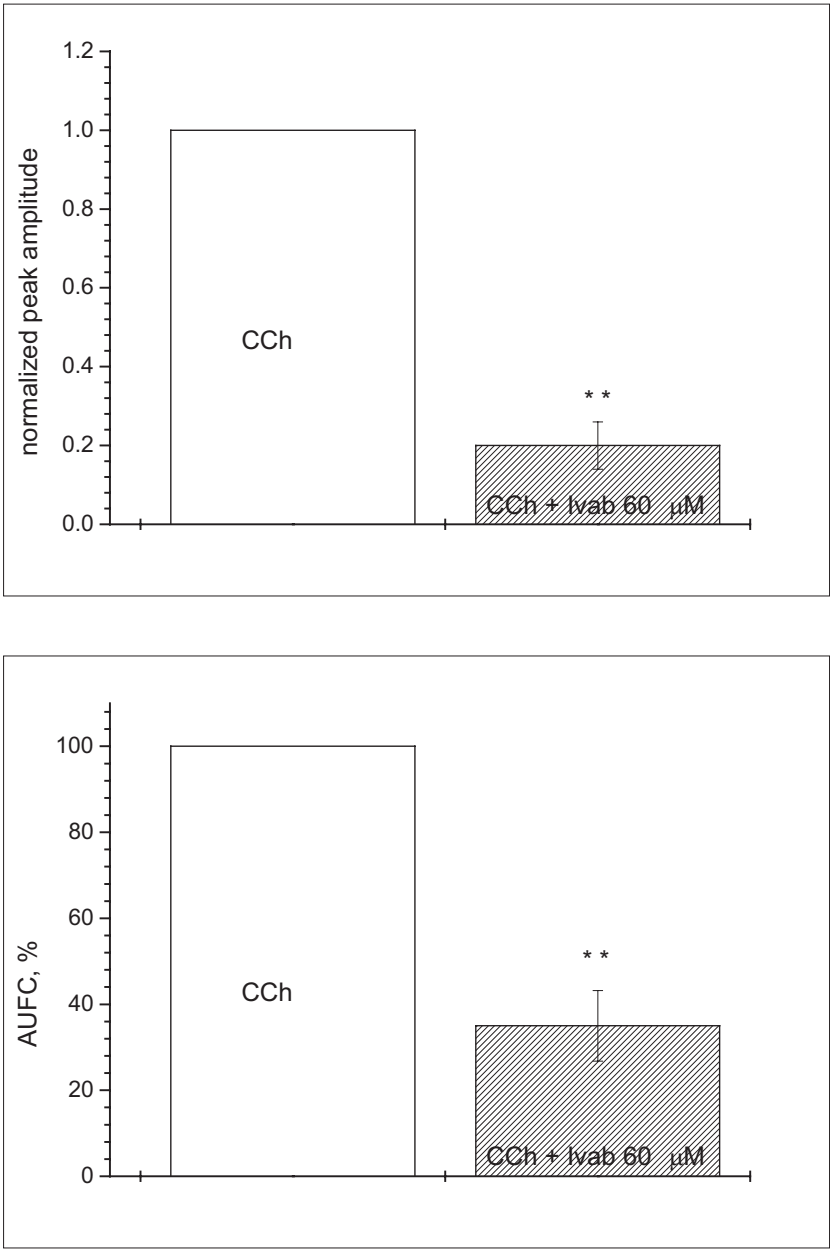

Fig. 2. Effect of $60 \mu \mathrm{M}$ ivabradine on the carbachol (CCh, $1 \mu \mathrm{M})$-induced contractions of rat bladder strips; normalized amplitude of CCh-evoked contractions and area under force-time curve (AUFC)

Results are expressed as mean \pm SE; * $p<0.01$ compared to the CCh-induced response period prior to ivabradine application $(n=7)$; ${ }^{* *} p<0.001$ compared to the CCh-induced response period prior to ivabradine application $(n=7)$.

Interstitial cells of Cajal play an important role in the regulation of the bladder excitation-contraction process, probably by providing the link between the neurogenic and myogenic mechanisms. The finding that normally single in nature ICCs predominantly appear as closely joined in unstable bladders, and the presence of a strong correlation between the density of ICCs and detrusor excitability further indicates this possibility. ${ }^{14}$ Furthermore, following spinal cord injury, which typically leads to a neurogenic bladder exhibiting urinary retention, there is a significantly lower number of ICCs in the rat urinary bladder. ${ }^{15,16}$ The $\mathrm{HCN}$ channels, which generate pacemaking currents, are present on the cell membranes of ICCs. Considering all these facts, it could be postulated that pacemaker current inhibitors might be useful in the treatment of OAB. In the present in vitro study, the amplitude of $\mathrm{CCh}$-induced contractions of rat bladder strips was inhibited by ivabradine in a concentrationdependent manner.
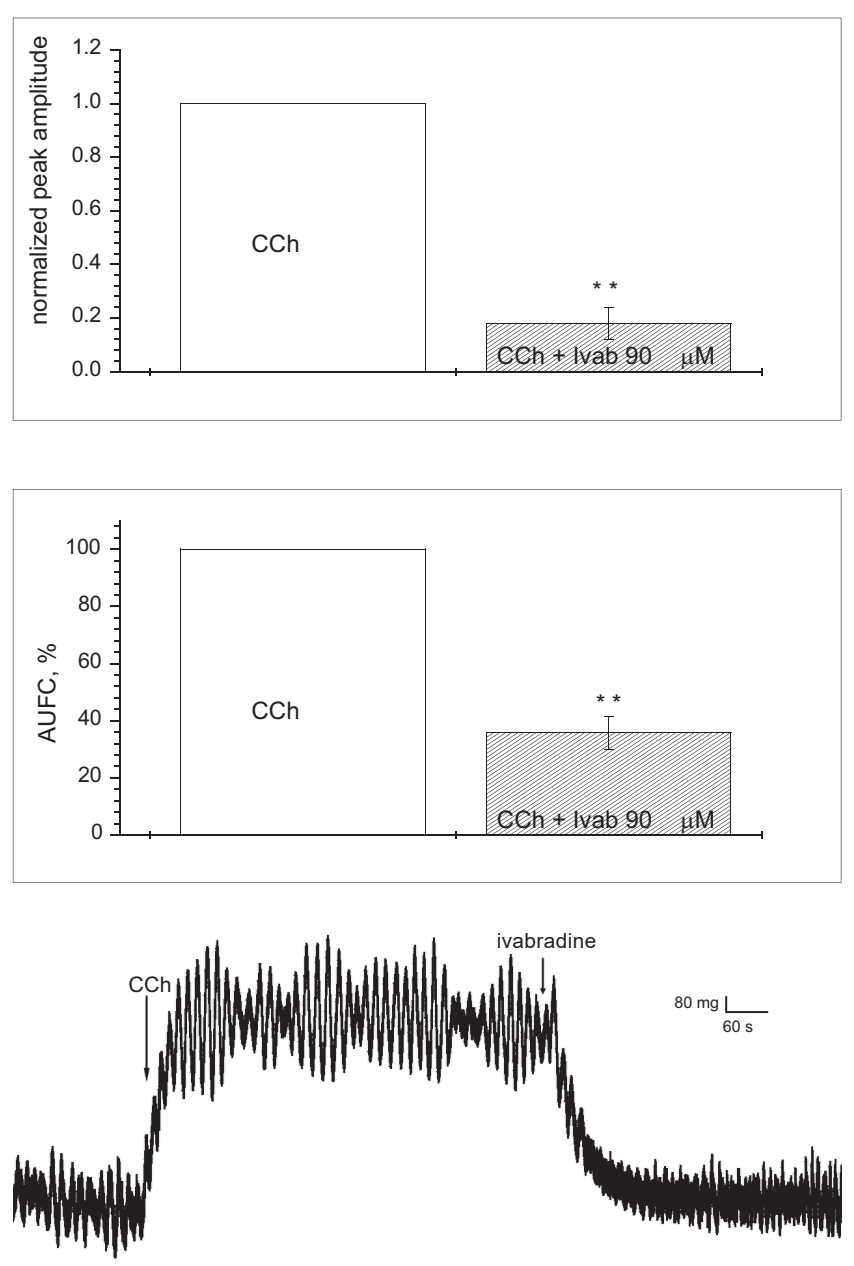

Fig. 3. Effect of $90 \mu \mathrm{M}$ ivabradine on the carbachol (CCh, $1 \mu \mathrm{M})$-induced contractions of rat bladder strips; normalized amplitude of CCh-evoked contractions and area under force-time curve (AUFC)

Results are expressed as mean $\pm \mathrm{SE} ;{ }^{*} \mathrm{p}<0.01$ compared to the CChinduced response period prior to ivabradine application $(n=7)$; ** $p<0.001$ compared to the CCh-induced response period prior to ivabradine application $(n=7)$.

A representative tracing illustrating the contractile activity of bladder strip preparations in response to carbachol (CCh, $1 \mu \mathrm{M})$ and the inhibition of the contractile activity by ivabradine. Bladder strips developed a sustained tension in response to CCh, and ivabradine was applied at the indicated point and was continuously present afterwards.

Similar to previous the in vitro studies using detrusor smooth muscles, the application of muscarinic receptor agonist CCh $(1 \mu \mathrm{M})$ evoked strong sustained tonic contractions. ${ }^{17,18}$ In cultured ICCs, the in vitro application of CCh was shown to cause an increase in intracellular calcium, intracellular signaling essential for the generation of pacemaker potentials and contraction, suggesting that bladder ICCs might play a role in the regulation of cholinergic stimulation-mediated bladder contraction. ${ }^{18-20}$ Although this information can help in the interpretation of the ivabradine effect on bladder contractility, we do not know whether the inhibitory effect of ivabradine obtained in the current study is mediated through ICCs. Although we have no direct evidence, the inhibitory actions of ivabradine on the rat detrusors might involve the modulation 


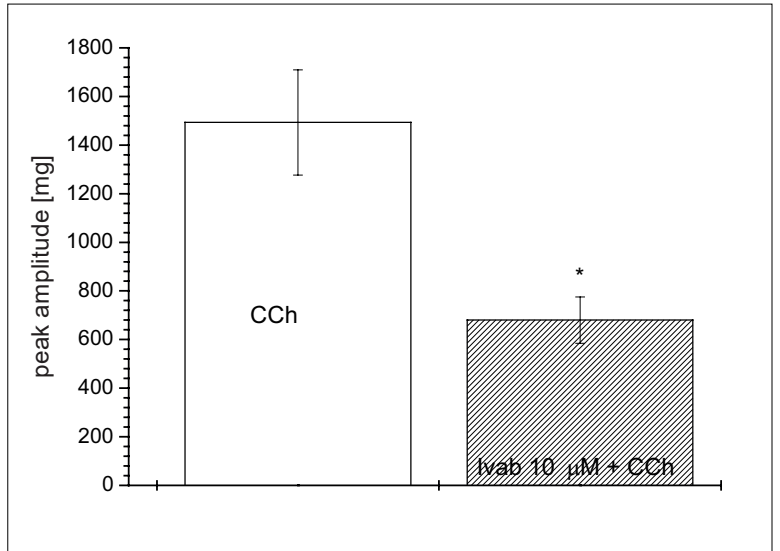

Fig. 4. Effect of $10 \mu \mathrm{M}$ ivabradine pre-treatment on the carbachol (CCh, $1 \mu \mathrm{M}$ )-induced contractions of rat bladder strips

${ }^{*} p<0.003$ compared to the CCh-induced response period prior to ivabradine application $(n=7)$.

of calcium release from the sarcoplasmic reticulum (SR). This is plausible, considering the role of $\mathrm{Ca}^{2+}$ released from the $\mathrm{SR}$ in regulating If in SA node preparations. ${ }^{21}$

In bladder overactivity, developed in a rat model following partial bladder outlet obstruction, it was shown that the physiological functioning of ICCs changes and the expression of the HCN channels in bladder ICCs significantly increases. ${ }^{22-24}$ These findings suggest that the HCN channels and ICCs might play an important role in the pathogenesis of detrusor overactivity. Thus, the involvement of the HCN channels is another possible mechanism mediating the inhibition of cholinergic agonist-induced bladder contraction by ivabradine. Considering this structural evidence, our findings of the inhibitory effect of ivabradine on CChinduced bladder contractility would be of importance in the management of $\mathrm{OAB}$.

The concentrations of ivabradine tested in the present study are higher (about 100-fold) than its achieved max plasma concentration, following the recommended dose of $5 \mathrm{mg}$ twice daily. This concentration is well-below the toxic dose reported in animal studies, although there is not enough clinical data revealing special hazards for humans. ${ }^{25}$ In a case of a purposeful intoxication attempt with $280 \mathrm{mg}$ of ivabradine, no serious complication, other than mild bradycardia, which was no more severe than the one observed with a therapeutic dosage, was reported. ${ }^{26}$ In any case, lower doses of ivabradine could be used in combination with available drugs (i.e., anticholinergics) that would provide efficacy and minimize the risk of unwanted effects.

\section{Conclusions}

In conclusion, the results of this in vitro study demonstrate that ivabradine inhibits cholinergic agonist-induced bladder contractions. It shows that ivabradine could be potentially used in the future, alone or in combination with currently used agents (i.e., anticholinergic) in OAB treatment.

\section{References}

1. Fry $\mathrm{CH}$, Meng $\mathrm{E}$, Young JS. The physiological function of lower urinary tract smooth muscle. Auton Neurosci. 2010;154:3-13.

2. Andersson $\mathrm{KE}$, Arner A. Urinary bladder contraction and relaxation: Physiology and pathophysiology. Physiol Rev. 2004;84:935-986.

3. Seth JH, Panicker JN, Fowler CJ. The neurological organization of micturition. Handb Clin Neurol. 2013;117:111-117.

4. Sugaya K, Nishijima S, Miyazato M, Ogawa Y. Central nervous control of micturition and urine storage. JSmooth Muscle Res. 2005;41:117-132.

5. Abrams $P$, Chapple $C R$, Jünemann KP, Sharpe $S$. Urinary urgency: A review of its assessment as the key symptom of the overactive bladder syndrome. World J Urol. 2012;30:385-392.

6. Apoznański W, Polok M, Rysiakiewicz J, et al. An evaluation of the effectiveness of external urethral meatus incision in girls with an anterior deflected urinary stream and symptoms of detrusor overactivity. Adv Clin Exp Med. 2014;23:283-287.

7. Verkerk AO, van Ginneken AC, Wilders R. Pacemaker activity of the human sinoatrial node: Role of the hyperpolarization-activated current, I(f). Int J Cardiol. 2009;132:318-336.

8. Kolęda P, Pilecki W. Nature of interstitial cells of Cajal of the upper urinary tract. Adv Clin Exp Med. 2014;23:627-632.

9. Siu CW, Lieu DK, Li RA. HCN-encoded pacemaker channels: From physiology and biophysics to bioengineering. J Membr Biol. 2006; 214:115-122.

10. Sanders KM, Ward SM, Koh SD. Interstitial cells: Regulators of smooth muscle function. Physiol Rev. 2014;94:859-907.

11. Takaki M, Suzuki H, Nakayama S. Recent advances in studies of spontaneous activity in smooth muscle: Ubiquitous pacemaker cells. Prog Biophys Mol Biol. 2012;102:129-135.

12. Postea O, Biel M. Exploring HCN channels as novel drug targets. Nat Rev Drug Discov. 2011;10:903-914.

13. Stamatiou K, Heretis I, Skoumbourdis E. Does ivabradine exhibit a role in the reduction of bladder overactivity? Int Urol Nephrol. 2008; 40:333-334.

14. Johnston L, Woolsey S, Cunningham RM, et al. Morphological expression of kit positive interstitial cells of Cajal in human bladder. $J$ Urol. 2010;184:370-377.

15. Johnston L, Cunningham RM, Young JS, et al. Altered distribution of interstitial cells and innervation in the rat urinary bladder following spinal cord injury. J Cell Mol Med. 2012;16:1533-1543.

16. Akino $\mathrm{H}$. Spontaneous contractile activity of the detrusor muscle and its role in the pathogenesis of overactive bladder syndrome. Low Urin Tract Symptoms. 2012;4:42-47.

17. Oh SJ, Ahn SC, Kim SJ, et al. Carbachol-induced sustained tonic contraction of rat detrusor muscle. BJU Int. 1999;84:343-349.

18. Hidayat Santoso AG, Liang W. Bladder contractility is mediated by different $\mathrm{K}+$ channels in the urothelium and detrusor smooth muscle. J Pharmacol Sci. 2011;115:127-134.

19. Johnston L, Carson C, Lyons AD, Davidson RA, McCloskey KD. Cholinergic-induced $\mathrm{Ca}^{2+}$ signaling in interstitial cells of Cajal from the guinea pig bladder. Am J Physiol Renal Physiol. 2008;294:F645-655.

20. Kim SO, Jeong HS, Jang S, et al. Spontaneous electrical activity of cultured interstitial cells of Cajal from mouse urinary bladder. Korean J Physiol Pharmacol. 2013;17:531-536.

21. Nazarov IB, Schofield CJ, Terrar DA. Contributions of cardiac "funny" (f) channels and sarcoplasmic reticulum $\mathrm{Ca} 2+$ in regulating beating rate of mouse and guinea pig sinoatrial node. Physiol Rep. 2015;3(12): e12561. doi:10.14814/phy2.12561

22. Kim SO, Oh BS, Chang IY, et al. Distribution of interstitial cells of Cajal and expression of nitric oxide synthase after experimental bladder outlet obstruction in a rat model of bladder overactivity. Neurourol Urodyn. 2011;30:1639-1645.

23. Fry $\mathrm{CH}$. Interstitial cells in the urinary tract, where are they and what do they do? BJU Int. 2014;114:434-435.

24. Deng T, Zhang Q, Wang Q, Zhong X, Li L. Changes in hyperpolarization-activated cyclic nucleotide-gated channel expression and activity in bladder interstitial cells of Cajal from rats with detrusor overactivity. Int Urogynecol J. 2015;26:1139-1145.

25. Colak MC, Parlakpinar H, Tasdemir S, et al. Therapeutic effects of ivabradine on hemodynamic parameters and cardiotoxicity induced by doxorubicin treatment in rat. Hum Exp Toxicol. 2012;31:945-954.

26. Mathiaux F, Dulaurent S, Julia F, Gaulier JM. Case report of ivabradine intoxication. J Anal Toxicol. 2014;38:231-232. 